\title{
Redactioneel
}

\section{De uitbreiding van de sluitingsbevoegdheid in artikel 174a Gemeentewet en de taak van de burgemeester als sheriff}

\author{
Mr. dr. drs. B. van der Vorm*
}

In de strijd tegen ondermijnende misdaad worden alle registers opengetrokken om zo effectief mogelijk op te kunnen treden. Op veel fronten worden bestaande juridische kaders nader versterkt. ${ }^{1}$ Zo kan worden gewezen op de anvullingen op het openbare-orderecht ten behoeve van de anpak van ondermijning. ${ }^{2}$ Een van nieuwe voornemens is om de sluitingsbevoegdheid van artikel 174a Gemeentewet (Wet Victoria) uit te breiden. Op grond van de huidige bepaling heeft de burgemeester de bevoegdheid om te 'besluiten een woning, een niet voor het publiek toegankelijk lokaal of een bij die woning of dat lokaal behorend erf te sluiten, indien door gedragingen in de woning of het lokaal of op het erf de openbare orde rond de woning, het lokaal of het erf wordt verstoord.' Uit het tweede lid van artikel 174a Gemeentewet blijkt dat de burgemeester de bevoegdheid ook mag toepassen, indien sprake is 'van ernstige vrees voor verstoring van de openbare orde op de grond dat de rechthebbende op de woning, het lokaal of het erf eerder een woning, een niet voor het publiek toegankelijk lokaal of een bij die woning of dat lokaal behorend erf op een zodanige wijze heeft gebruikt of doen gebruiken dat die woning, dat lokaal of dat erf op grond van

* Mr. dr. drs. B. van der Vorm is universitair docent straf(proces)recht en is verbonden aan het Willem Pompe Instituut voor Strafrechtswetenschappen en het Montaigne Centrum voor Rechtsstaat en Rechtspleging van de Universiteit Utrecht. Hij is tevens redacteur van dit tijdschrift.

1. E.W. Kolthoff, 'Aanpak van ondermijning. Een balans van juridische en bestuurlijke instrumenten', in: E.W. Kolthoff \& J.W. Sap (red.), De veilig stad als collectief doel, Nijmegen: Ars Aequi Libri 2019, p. 67-79.

2. M.I. Tuk \& M. Vols, 'Ondermijning en het openbare-orderecht', NJB 2018, p. 1704-1711. het eerste lid is gesloten, en er aanwijzingen zijn dat betrokkene de woning, het lokaal of het erf ten aanzien waarvan hij rechthebbende is eveneens op een zodanige wijze zal gebruiken of doen gebruiken.' Het tweede lid van deze bepaling kan worden beschouwd als een voorbeeld van preventieve bestuurlijke rechtshandhaving door Rogier in zijn tweede Rotterdamse oratie ooit aangeduid als past performance van de overtreder. ${ }^{3}$

Duidelijk is dat deze bevoegdheid nauw samenhangt met een (vrees voor een) verstoring van de openbare orde. Op dit aspect wijkt de sluitingsbevoegdheid van artikel 174a Gemeentewet af van artikel 13b Opiumwet. Voor de toepassing van de laatstgenoemde bevoegdheid is een verstoring van de openbare orde of vrees daarvoor niet vereist. In de praktijk wordt artikel 13b Opiumwet gebruikt om drugsoverlast aan te pakken en artikel 174a Gemeentewet voor andere overlast. Gedacht kan worden aan de volgende mogelijkheden: een woningsluiting 'onduldbare overlast van een grote reptielenverzameling, of vanwege overlast van prostitutie, mensenhandel of niet meer te accepteren overlast van asociale gezinnen.' ${ }^{4}$ De praktijk laat echter zien dat deze bevoegdheid nauwelijks worden toegepast, omdat het lastig te bewijzen is dat de gedragingen in de woning de ordeverstoring rond de woning hebben veroorzaakt. ${ }^{5}$

3. L.J.J. Rogier, Preventieve bestuurlijke rechtshandhaving (oratie Rotterdam), Den Haag: Boom juridische uitgevers 2006.

4. H.J.B. Sackers, 'Commentaar op artikel 174a Gemeentewet', in: C.P.M. Cleiren, J.H. Crijns \& M.J.M Verpalen (red.), Tekst \& Commentaar Strafvordering, Deventer: Wolters Kluwer (boek en online).

5. R. Salet \& H.J.B. Sackers, 'Spanningen tussen de bestuurlijke en strafrechtelijke aanpak van criminaliteit', NJB 2019, p. 935. 
Zowel de woningsluiting op grond van artikel 13b Opiumwet alsook artikel 174a Gemeentewet wordt niet aangemerkt als een bestraffende sanctie. Als uitgangspunt geldt dat de bevoegdheid van artikel 13b Opiumwet een niet-punitief karakter heeft, zo blijkt ook uit bestendige jurisprudentie van de Afdeling. ${ }^{6}$ Hierbij dient wel te worden opgemerkt dat artikel 13b Opiumwet steeds vaker punitief wordt ingezet door de burgemeester en dit ook de Afdeling is opgevallen. ${ }^{7}$ Als deze lijn wordt doorgezet, kan dit gevolgen hebben voor de ontvankelijkheid van het Openbaar Ministerie. ${ }^{8}$ Over deze kwestie zijn vragen gesteld aan de minister van Justitie en Veiligheid. ${ }^{9}$ De minister is niet bang dat de toepassing van artikel $13 \mathrm{~b}$ Opiumwet zal leiden tot een niet-ontvankelijkheid van het Openbaar Ministerie:

'Burgemeesters hoeven niet te motiveren maarom de sluiting géén punitieve sanctie is. Wel moet morden uitgelegd maarom de sluiting - als herstelsanctie - niet verder gaat dan mat noodzakelijk is om de overtreding te beëindigen en herhaling daarvan te voorkomen. Tevens moet in het besluit morden uitgelegd maarom de sluiting voor de belanghebbenden geen nadelige gevolgen heeft die onevenredig zijn in verhouding tot het doel van de sluiting (artikel 3:4, tweede lid, van de Algemene pet bestuursrecht (Amb)). De uitspraak van november 2017 geeft geen reden tot zorg over een eventuele latere strafrechtelijke vervolging, al was het maar omdat uit de uitspraak van oktober 2018 blijkt dat ook in die zaak geen sprake mas van een criminal charge. 10

Stelt dit antwoord van de minister gerust? Ik zou toch menen van niet. Enerzijds, omdat de minister ten onrechte veel waarde hecht aan de uitspraak van de Afdeling uit 2018. De argumentatie dat de sluiting een herstelsanctie is - in de uitspraak van de Afdeling uit oktober 2018 - is weinig steekhoudend. Het is een pure cirkelredenering, waar de Afdeling genoegen mee neemt, zo geven de annotatoren Brouwer en Bruijn terecht aan. ${ }^{11}$ Het heeft er dus alle schijn van dat de Afdeling met deze uitspraak niet heeft willen doorpakken. Anderzijds blijkt uit onderzoek dat de toepassing van artikel $13 \mathrm{~b}$ Opiumwet in de praktijk een louter vergeldend en bestraffend karakter heeft gekregen, in plaats van gericht op herstel van de illegale situatie (of de openbare orde) of beëindiging of voorkoming van overtreding van de Opiumwet. ${ }^{12}$ Hoewel deze bevoegdheid op schrift het karakter heeft van een bestuurlijke herstelsanctie lijkt de toepassing ervan steeds meer punitief

6. B. van der Vorm, 'De sanctiebevoegdheid van de burgemeester in artikel 13b Opiumwet', TBS\&H 2017, p. 167-170.

7. ABRvS 29 november 2017, ECLI:NL:RVS:2017:3251, Gst. 2018/39, m.nt. A. Schreijenberg.

8. B. van der Vorm, 'De sluitingsbevoegdheid van artikel 13b Opiumwet: een mogelijk vervolgingsbeletsel voor het Openbaar Ministerie', PROCES 2019, p. 40-52.

9. Kamerstukken I/ 2018/19, nr. 2411 (Aanhangsel).

10. Kamerstukken I/ 2018/19, nr. 2411 (Aanhangsel), p. 2.

11. Zie de derde en vierde opmerking van J.G. Brouwer \& L.M. Bruijn onder ABRvS 24 oktober 2018, ECLI:NL:RVS:2018:3482, AB 2019/514.

12. Salet \& Sackers 2019, p. 937. te worden. Een dergelijke ontwikkeling kan dus zeker gevolgen hebben voor de ontvankelijkheid van het Openbaar Ministerie en een mogelijk vervolgingsbeletsel worden. De discussie over het al dan niet bestraffende karakter van artikel 13b Opiumwet is zeer zeker nog niet beslist, zo is mijn verwachting.

Waar de relatie met de handhaving van de openbare orde in artikel 13b Opiumwet is losgelaten, wordt deze relatie in het huidige artikel 174a Gemeentewet wel gelegd. De verstoring van de openbare orde moet cumulatief een ernstige aantasting van de veiligheid en de gezondheid inhouden voor de omgeving van de woning. ${ }^{13}$ Dit maakt het voor de burgemeester niet eenvoudig om toepassing te geven aan deze bevoegdheid: uitsluitend wanneer de openbare-ordeverstoring van dien aard is dat die een bedreiging vormt voor de veiligheid en gezondheid van mensen, en wanneer die overlast uitsluitend of overwegend vanuit de te sluiten woning is ontstaan. ${ }^{14}$ Het gaat te ver om de sluitingsbevoegdheid van artikel 174a Gemeentewet als een dode bevoegdheid aan te merken, maar van grote praktische betekenis is deze bepaling, zoals eerder is opgemerkt, geenszins. Toch zijn er vergaande plannen om artikel 174a Gemeentewet uit te breiden. Deze uitbreiding van artikel 174a Gemeentewet vloeit rechtstreeks voorts uit het voornemen van het kabinet om juridische knelpunten in de aanpak van ondermijnende misdaad aan te pakken. Een van deze juridische knelpunten heeft betrekking op artikel 174a Gemeentewet. Deze huidige bevoegdheid is niet toereikend om op te treden bij ernstig geweld of het aantreffen van een wapen, zo blijkt uit de memorie van toelichting bij het 'Wetsvoorstel wijziging Gemeentewet ten behoeve van sluiten woning bij verstoring openbare orde door ernstig geweld of wapens'. In de memorie van toelichting wordt gewezen op een casus, waarbij op verschillende momenten explosieven in de richting van de woning van een president van een outlam motorcycle gang (Bandidos MC te Sittard) werden gegooid, hetgeen tot schade leidde aan de woning, de naastgelegen woningen en geparkeerde auto's. De burgemeester gaf naar aanleiding van dit gebeuren toepassing aan artikel 174a, eerste lid, Gemeentewet en sloot de woning van de president. De Afdeling overweegt - in navolging van de rechtbank dat de burgemeester onrechtmatig gebruik heeft gemaakt van de sluitingsbevoegdheid van artikel $174 \mathrm{a}$ Gemeentewet:

'Met de rechtbank wordt vooropgesteld dat het gooien van explosieven richting de moning van [mederpartij] zonder meer kan worden aangemerkt als een ernstige verstoring van de openbare orde en dat het gelet daarop begrijpelijk is dat de burgemeester het nodig achtte in te

13. M. Vols, 'Commentaar op artikel 174a Gemeentewet', in: E.R. Muller, E.T. Brainich, J.G. Brouwer \& A.E. Schilder (red.), Tekst \& Commentaar Openbare orde en veiligheid, Deventer: Wolters Kluwer (boek en online).

14. A.E.M. van den Berg, 'Woonoverlast', in: A.E.M. van den Berg, J.H.A. van der Grinten \& A.E. Schilder (red.), Hoofstukken openbare-orderecht, Nijmegen: Ars Aequi Libri 2015, p. 97. 
grijpen en de veiligheid en rust in de straat te herstellen. Dat betekent echter nog niet dat de burgemeester reeds daarom bevoegd mas tot toepassing van artikel 174 a, eerste lid, van de Gemeentemet. De rechtbank heeft terecht overwogen dat niet aan de voormaarden voor toepassing van dat artikel is voldaan, nu de verstoring van de openbare orde in dit geval het gevolg mas van explosieven die van buitenaf richting de woning werden gegooid en derhalve niet van gedragingen in de poning. Voor zover de burgemeester heeft betoogd dat de gedraging in de moning als bedoeld in artikel 174 a, eerste lid, van de Gemeentemet "het bemonen van de moning door [mederpartij] in de hoedanigheid van president van een chapter van Bandidos" is, mordt overmogen dat de rechtbank deze redenering terecht niet heeft gevolgd. De rechtbank heeft daartoe met juistheid overmogen dat melismaar aannemelijk is dat het gooien van de explosieven samenhing met de installatie van [mederpartij] als president van een chapter van de Bandidos, maar dat de persoon of positie van een persoon niet kan worden gezien als gedraging als bedoeld in voormeld artikel. Dit geldt naar het oordeel van de Afdeling ook voor het bemonen van een moning door een bepaald persoon of een persoon met een bepaalde positie. Gelet hierop heeft de rechtbank terecht geconcludeerd dat de burgemeester niet bevoegd mas de moning van [mederpartij] op grond van artikel 174 a, eerste lid, van de Gemeentemet te sluiten.' 15

Uit artikel 174, eerste lid, Gemeentewet, vloeien drie vereisten voort, waaraan moet worden voldaan: er moet sprake zijn van (1) een gedraging in de woning, (2) een verstoring van de openbare orde en van (3) een causaal verband tussen de gedraging in de woning en de verstoring. ${ }^{16}$ In casu was echter geen sprake van een gedraging in de woning, waardoor artikel 174a, eerste lid, Gemeentewet, door de burgemeester onrechtmatig is toegepast. Om ondermijnende misdaad effectief te kunnen aanpakken middels artikel 174a Gemeentewet, is voorgesteld om deze bevoegdheid van de burgemeester uit te breiden. Er is voorgesteld om naast de huidige sluitingsgrond twee nieuwe sluitingsgronden aan artikel 174 , eerste lid, Gemeentewet toe te voegen. In de eerste plaats wordt het mogelijk de woning te sluiten wanneer door ernstig geweld, of bedreiging daarmee, in of in de onmiddellijke nabijheid van de woning of het lokaal of op het erf of in de onmiddellijke nabijheid van het erf, de openbare orde rond de woning, het lokaal of het erf wordt verstoord of ernstige vrees bestaat voor het ontstaan daarvan (eerste lid, onderdeel b). In de tweede plaats wordt het mogelijk de woning te sluiten indien, door het aantreffen in de woning of het lokaal of op het erf van een wapen als bedoeld in artikel 2 van de Wet wapens en munitie, de openbare orde rond de woning, het lokaal of het erf wordt verstoord of ernstige vrees

15. ABRvS 5 april 2017, ECLI:NL:RVS:2017:923, JG 2017/45, m.nt. J. Koornstra \& M. Vols.

16. Zie de vierde opmerking in de annotatie van Koornstra \& Vols onder ABRvS 5 april 2017, ECLI:NL:RVS:2017:923, JG 2017/45. bestaat voor het ontstaan daarvan (eerste lid, onderdeel c).

In de memorie van toelichting wordt expliciet aangeven dat met de verruiming van artikel $174 \mathrm{a}$, eerste lid, Gemeentewet, de burgemeester niet moet worden aangemerkt als een handhaver van de Wet wapens en munitie. Als we de memorie van toelichting moeten geloven blijft de burgemeester als hij toepassing geeft aan deze nieuwe sluitingsbevoegdheden een handhaver van de openbare orde, maar is dit wel zo? Niet iedere burgemeester is hiervan overtuigd. Burgemeester Buijs van de gemeente Oss is niet overtuigd van de mogelijkheid om een woning te sluiten na de vondst van wapens.

'Ook voor mij is het onverteerbaar dat mensen pistolen en andere mapens in huis hebben. De vraag is of zoiets direct gekoppeld kan worden aan de handhaving van openbare orde en veiligheid en dat er dus een taak voor de burgemeesters ligt. Het verschil met drugs is dat deze vaak een grote aantrekkingskracht hebben op allerlei gespuis (...). Door een moning te sluiten haal je de loop eruit. Bovendien is er bij hennepkmekerijen en drugslaboratoriums ook nog het risico op brand, waar ook de buurt aan bloot mordt gesteld. '17

Hier komen we tot de kern van de zaak: hoe verhoudt deze voorgenomen uitbreiding van de sluitingsbevoegdheid van de burgemeester zich tot de wettelijke taak van de handhaving van de openbare orde? Vloeit deze uitbreiding voort uit het bepaalde van artikel 172, eerste lid, Gemeentewet? De burgemeester heeft op grond van artikel 172, eerste lid, Gemeentewet, de taak tot handhaving van de openbare orde, maar is de burgemeester die toepassing geeft aan de nieuwe sluitingsgronden niet vooral aan te merken als een misdaadbestrijder of sheriff? Indien een burgemeester een woning sluit, omdat in die woning boksbeugels, ploertendoders en wurgstokken zijn gevonden, en een ernstige vrees bestaat dat de openbare orde rond die woning wordt verstoord, kan dan nog worden beweerd dat de burgemeester niet is aan te merken als een wetshandhaver? Hoewel de Afdeling advisering van de Raad van State negatief staat tegenover een uitbreiding van het openbare-ordebegrip in de zin dat hier ook de aanpak van misdaad onder valt, ${ }^{18}$ leidt de toename van de bevoegdheden van de burgemeester tot rechtsstatelijke vragen. Dient de rechtsstatelijke taak van de burgemeester niet nader te worden bezien? Het is moeilijk voorstelbaar dat de uitbreiding van de sluitingsbevoegdheid in artikel 174a, eerste lid, Gemeentewet, niets van doen heeft met de taak van de burgemeester als misdaadbestrijder. Zeker nu deze uitbreiding een gevolg is van de aanpak tegen ondermijnende misdaad, is het belangrijk om het taken-

17. 'Burgemeester Buijs twijfelt over woningsluiting na wapenvondst', Brabants Dagblad 11 september 2018.

18. Verzoek om voorlichting over de rol van gemeenten in de bestuurlijke en integrale aanpak van ondermijning, p. 14-15. Zie ook 'Raad van State over rol gemeenten bij aanpak ondermijnende criminaliteit', NJB 2019, p. 999 
pakket van de burgemeester nader te bezien. De uitbreiding van de sluitingsbevoegdheid conflicteert met de rol van de burgemeester als burgervader. In zijn oratie is door Sackers reeds opgemerkt dat deze taak op gespannen voet staat met de openbare-ordetaak van de burger. ${ }^{19}$ De uitbreiding van de sluitingsbevoegdheid gaat mogelijk verder dan uitsluitend de handhaving van de openbare orde en neigt naar een rol van de burgemeester in de bestuurlijke aanpak van ondermijning.

Hoe nu verder? Er lijkt sprake te zijn van een discrepantie tussen de wettelijke taak van de handhaving van de openbare orde en de ontwikkeling van nieuwe bevoegdheden onder het mom van de handhaving van de openbare orde. Het is zonneklaar dat de burgemeester een taak heeft in de bestuurlijke aanpak van ondermijning; deze taak is echter niet wettelijk neergelegd. Bezien in dat perspectief acht ik het niet onwenselijk dat artikel 172 , eerste lid, Gemeentewet, wordt uitgebreid in de zin dat de burgemeester ook een wettelijke taak krijgt in de bestuurlijke aanpak van misdaad. Met nadruk wordt gewezen op de bestuurlijke aanpak van misdaad, want de burgemeester dient niet te worden uitgerust met strafvorderlijke bevoegdheden. Een dergelijke uitbreiding van artikel 172, eerste lid, Gemeentewet, zou aansluiten bij de toepassingspraktijk van bestaande bevoegdheden. Een burgemeester kan op grond van artikel 44a, eerste lid, Drank- en Horecawet, een bestuurlijke boete opleggen wegens bijvoorbeeld overtreding van het verbod om zonder daartoe strekkende vergunning een horecabedrijf of slijtersbedrijf uit te oefenen. Heeft een oplegging van een dergelijke bestraffende sanctie iets van doen met de handhaving van de openbare orde? Het antwoord op deze vraag luidt ontkennend; de burgemeester treedt dan bestraffend op tegen een overtreding van een norm uit de Drank- en Horecawet. De slotsom is dat de burgemeester reeds méér kan dan uitsluitend de handhaving van de openbare orde. Ook is geaccepteerd dat de burgemeester een taak heeft in de bestuurlijke aanpak van misdaad. Dit zijn geen nieuwe inzichten. ${ }^{20}$ Er bestaat een discrepantie tussen law in action (de burgemeester als sheriff) en law in books (de burgemeester als handhaver van de openbare orde). Vols waarschuwt voor de burgemeester als sheriff en geeft aan dat een dergelijke taak zal leiden tot ingrijpende veranderingen in de gemeentelijke organisatie: de ontwikkeling van de gemeente als veiligheidsorganisatie. ${ }^{21}$ Is een dergelijke ontwikkeling echter niet reeds ingezet met de veiligheidshuizen? Er is sprake van een situatie, waarbij de burgemeester in de praktijk kan worden aangemerkt als een sheriff, terwijl de burgemeester deze taak niet wettelijk heeft. Ik ben het met Vols eens dat kan worden afgevraagd in hoeverre deze praktijk vanuit een juridisch-normatief perspectief legitiem is. ${ }^{22} \mathrm{Om}$ hieraan tegemoet te komen, bestaan er naar mijn mening goede redenen (mede vanuit het legaliteitsbeginsel beredeneerd, dat overheidsoptreden moet rusten op een wettelijke grondslag) om de burgemeester de wettelijke taak te geven van bestuurlijke bestrijder van misdaad.
19. H.J.B. Sackers, Herder, hoeder en handhaver. De burgemeester en het bestuurlijke sanctierecht (oratie Nijmegen), Nijmegen: Radboud Universiteit Nijmegen 2010, p. 35-36.

20. A.C.M. Spapens, 'Bestuurlijke aanpak van ondermijning: ervaringen in Nederland en het buitenland', TBS\&H 2019, p. 92.

21. M. Vols, 'Ondermijning: van frame naar hype naar wet. Een bespreking van de preadviezen Jonge VAR 2019', NTB 2020, p. 51-52.
22. Vols 2020, p. 52. Zie ook: R. Salet, J. Terpstra \& M.A.D.W. de Jong, 'Ondermijningsaanpak. Is de boodschap van Van Traa vergeten?', Christendemocratische Verkenningen 2019, p. 96-97. 